\section{Diagnostic and Therapeutic Strategy for Female Patients With Cardiac Amyloidosis}

To the Editor:

Sex differences in various diseases have received considerable attention. Ochi et al demonstrated that the prevalence of wild-type transthyretin amyloidosis in female patients was higher than in previous reports. ${ }^{1}$ Female patients tended to have heart failure symptoms despite mild cardiac hypertrophy and preserved ejection fraction. Several concerns have been raised.

In the study of Ochi et al, the thickness of the left ventricular wall was less in female than male patients. ${ }^{1}$ Thus, it may be more challenging to suspect cardiac amyloidosis in daily clinical practice among female patients. Were there any differences in the signs and chief complaints between female and male patients? Female patients may have extracardiac symptoms more frequently than male patients.

Given the difficulty in diagnosis, there may have been a selection bias in the study. ${ }^{1}$ Of note, clinicians may not necessarily attempt to aggressively diagnose cardiac amyloidosis, particularly in elderly patients, given the lack of a definitive therapeutic strategy. Even the use of the recently introduced tafamidis may be challenging in elderly patients with advanced cardiac amyloidosis because of cost-effectiveness considerations. ${ }^{2}$ Do Ochi et al aggressively attempt to diagnose cardiac amyloidosis even in elderly patients?

The next concern following the diagnosis of cardiac amyloidosis is the therapeutic strategy. Approximately $15 \%$ of female and $40 \%$ of male patients had a mid-range or reduced ejection fraction. ${ }^{1}$ The use of neurohormonal blockers in patients with cardiac amyloidosis is controversial. ${ }^{3}$ Do Ochi et al prescribe neurohormonal blockers for such a cohort?

\section{Disclosures}

None.

\section{References}

1. Ochi Y, Kubo T, Baba Y, Sugiura K, Ueda M, Miyagawa K, et al. Wild-type transthyretin amyloidosis in female patients: Consideration of sex differences. Circ Rep 2021; 3: 465-471.

2. Nakamura $M$, Imamura $T$, Hori $M$, Ushijima $R$, Joho $S$, Kinugawa $\mathrm{K}$. Initial experience with tafamidis treatment for transthyretin amyloid cardiomyopathy. Circ Rep 2020; 2: $420-$ 424.

3. Aimo A, Vergaro G, Castiglione V, Rapezzi C, Emdin M. Safety and tolerability of neurohormonal antagonism in cardiac amyloidosis. Eur J Intern Med 2020; 80: 66-72.

Teruhiko Imamura, MD, PhD

Makiko Nakamura, MD, PhD

Second Department of Internal Medicine, University of Toyama, Toyama, Japan

Received September 8, 2021; accepted September 9, 2021; J-STAGE Advance Publication released online November 11, 2021

Mailing address: Teruhiko Imamura, MD, PhD, FAHA, FACC, FESC, FHFSA, FAPSC, FACP, FICA, FASA, FJCC, Second Department of Internal Medicine, University of Toyama, 2630 Sugitani, Toyama 930-0194, Japan. E-mail: teimamu@med. u-toyama.ac.jp

All rights are reserved to the Japanese Circulation Society. For permissions, please e-mail: cr@j-circ.or.jp

ISSN-2434-0790 